УДК 574.583(285.2):591

\author{
В. Н. Столбунова
}

Институт биологии внутренних вод им. И. Д. Папанина РАН

\title{
ЗООПЛАНКТОН оз. ЯХРОБОЛЬСКОЕ (Ярославская обл.)
}

Изучен зоопланктон оз. Яхробольское (Ярославская обл.) в заросшей макрофитами литорали и открытом плесе водоема в период активного функционирования сообщества. Неболышая глубина и близкие экологические условия в разных частях озера определяют слабо выраженную специфичность видовой структуры зоопланктонных комплексов. Максимум плотности и биомассы зоопланктона прослеживается в заросшем мелководье. Значительную часть численности составляют младшие возрастные стадии Сорерода, кормовые объекты молоди рыб-планктофагов. Озеро Яхробольское характеризуется как эвтрофный водоем.

\section{В. Н. Столбунова}

Інститут біології внутрішніх вод ім. І. Д. Папаніна РАН

\section{ЗООПЛАНКТОН оз. ЯХРОБОЛЬСЬКЕ (Ярославська обл.)}

Досліджено зоопланктон оз. Яхробольське (Ярославська обл.) у зарослій макрофітами літоралі та відкритому плесі водойми у період активного функціонування угруповання. Невелика глибина та близькі екологічні умови в різних частинах озера визначають слабко виражену специфічність видової структури зоопланктонних комплексів. Максимум щільності та біомаси зоопланктону прослідковусться у зарослому мілководді. Значну частину чисельності складають молодші вікові стадії Сорерода, кормові об'єкти молоді риб-планктофагів. Озеро Яхробольське характеризується як евтрофна водойма.

\author{
V. N. Stolbunova \\ Institute of Biology of Inland Waters, Russian Academy of Sciences
}

\section{ZOOPLANKTON IN YAKHROBOLSKOYE LAKE (Yaroslavl province)}

Zooplankton in the Lake Yakhrobolskoye was studied in the littoral overgrown with macrophytes and in the open part of the lake during the period of active functioning of zooplankton. The lake is not deep and has similar ecological conditions in its different parts that determine its weakly expressed specificity of the species composition of zooplankton complexes. The maximal density and biomass of zooplankton were recorded in the overgrown shallow part. Juvenile stages of copepods as food objects of plankton feeding fish are the most abundant in the lake. The lake is characterized as a eutrophic water body.

\section{Введение}

Озеро Яхробольское находится в пределах Некрасовской поймы Ярославской области. С севера в озеро впадают реки Исада и Сохма, с северо-востока - ручей Мутоловский, который берет начало в оз. Шачебольское. Вытекает из озера р. Рыбинка, впадающая в Горьковское водохранилище. Площадь водоема составляет около 400 га, наибольшая глубина -2 м, основные глубины - 1,0-1,3 м. Озеро сильно заросшее, свободна от водной растительности только небольшая часть плеса. Из макрофитов наиболее характерен двукисточник тростниковидный, камыш озерный, хвощ приречный,

(C) В. Н. Столбунова, 2010 
осоки, рдесты и др. Почти всю площадь дна покрывает сапропелевый ил. Взмучивание и обильное развитие фитопланктона обусловливают малую (до $60 \mathrm{~cm}$ ) прозрачность воды этого обширного и очень мелководного водоема. Воду озера следует относить к гидрокарбонатному классу [4].

Первые сведения о зоопланктоне оз. Яхробольское чрезвычайно незначительны и относятся к сентябрю 1963 г. [5]. По данным авторов, численность зоопланктона в

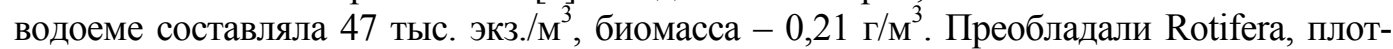
ность и биомасса которых достигали соответственно 90 и $98 \%$ от общей. Из руководящих коловраток указывался Brachionus diversicornis. Среди Cladocera в незначительном числе встречалась Bosmina longirostris, из Copepoda - науплиальные стадии Cyclopoida.

Ввиду того, что оз. Яхробольское часто используется в качестве рекреационных угодий, в основном для спортивного и любительского лова рыбы, в 2009 г. проанализированы состояние кормовой базы и состав ихтиофауны данного водоема.

Цель настоящей работы состояла в выяснении видового состава и количественной характеристики зоопланктона как кормовой базы рыб-планктофагов в заросших макрофитами мелководьях и открытом плесе оз. Яхробольское.

\section{Материал и методы исследований}

Материалом послужили сборы зоопланктона, проведенные в начале августа 2009 года в заросшей высшей водной растительностью литорали (станции $1,3-10$ ) и открытом плесе озера (станция 2). Зоопланктон собирали фильтрованием 50 л воды через планктонную сеть с ячеей 64 мкм. Пробы фиксировали 4 \% формалином. Камеральную обработку материала проводили по стандартной методике [2]. Зоопланктон оценивали по видовому составу, числу видов и доминантов, численности $(N)$, биомассе $(B)$, средней индивидуальной массе зоопланктера $\left(W_{c p}\right)$, соотношению между различными таксономическими группами [1]. Использовали показатели биоразнообразия [3]: $D_{M g}$ - видовое богатство по Маргалефу, $H$, бит/экз. - индекс видового разнообразия Шеннона $\left(H_{N}-\right.$ по численности, $H_{B}$ - по биомассе), индекс доминирования $d$ Бергера Паркера, а также индекс трофности Мяэметса $(E)$. В период исследований температура воды колебалась в пределах $+21,1 \ldots+25,2{ }^{\circ} \mathrm{C}$, глубина исследованных станций изменялась от 0,5 до 2 м.

\section{Результаты и их обсуждение}

В ходе исследований обнаружено 62 вида организмов зоопланктона, из которых Rotifera - 35, Copepoda - 8, Cladocera - 19 (табл. 1). Наиболее широко представлены коловратки. Среди них на всех станциях преобладал Brachionus diversicornis homoceros. Из ракообразных менее разнообразны Сорерода. Наибольшее число видов отмечено в заросшей макрофитами литорали. Благодаря тому, что условия обитания зоопланктеров ограничены незначительными глубинами и близкими экологическими условиями в разных частях озера, качественный состав зоопланктона литорали сходен с открытым плесом. Однако в заросшем мелководье наблюдается значительно бо́льшее разнообразие Crustacea, особенно ветвистоусых (см. табл. 1). Основу численности и биомассы на всех станциях, за исключением ст. 7 у д. Яхробол, где в массе развивался Brachionus (показатель загрязнения), составляли младшие возрастные стадии веслоногих ракообразных Thermocyclops oithonoides, Eucyclops macruroides и Mesocyclops leuckarti. Несмотря на то, что доля Cladocera мала (см. табл. 1), все же просматривалась тенденция к преобладанию мелкой Bosmina longirostris. 
Видовой состав зоопланктона на исследованных станциях оз. Яхробольское

\begin{tabular}{|c|c|c|c|c|c|c|c|c|c|c|}
\hline \multirow{2}{*}{ Вид } & \multicolumn{10}{|c|}{ Станция } \\
\hline & 1 & 2 & 3 & 4 & 5 & 6 & 7 & 8 & 9 & 10 \\
\hline 1 & 2 & 3 & 4 & 5 & 6 & 7 & 8 & 9 & 10 & 11 \\
\hline \multicolumn{11}{|c|}{ ROTIFERA } \\
\hline \multicolumn{11}{|l|}{ Ceм. Trichocercidae } \\
\hline Trichocerca cavia (Gosse, 1886) & - & - & + & - & - & - & - & - & - & - \\
\hline T. capucina (Wierzejski et Zacharias, 1893) & - & + & - & - & - & - & - & - & - & - \\
\hline T. iernis (Gosse, 1887$)$ & - & + & - & + & - & - & - & - & - & - \\
\hline T. inermis (Linder, 1904) & - & - & - & - & - & - & - & - & - & + \\
\hline T. tenuior (Gosse, 1886) & - & + & - & - & - & - & - & - & - & - \\
\hline T. similis (Wierzejski, 1893) & - & - & + & - & - & + & + & + & - & + \\
\hline \multicolumn{11}{|l|}{ Cем. Synchaetidae } \\
\hline Polyarthra major Burckhardt, 1900 & - & + & + & - & + & + & + & + & - & - \\
\hline P. minor Voigt, 1904 & + & + & + & - & + & + & + & - & + & + \\
\hline P. vulgaris Carlin, 1943 & + & + & - & + & + & - & - & + & - & - \\
\hline \multicolumn{11}{|l|}{ Сем. Asplanchnidae } \\
\hline Asplanchna herricki Guerne, 1888 & + & + & - & - & - & + & + & - & - & - \\
\hline A. priodonta Gosse, 1850 & + & + & + & + & + & + & + & + & + & + \\
\hline \multicolumn{11}{|l|}{ Cем. Mytilinidae } \\
\hline Mytilina ventralis (Ehrenberg, 1832) & - & - & - & - & - & - & + & - & - & - \\
\hline \multicolumn{11}{|l|}{ Cем. Euchlanidae } \\
\hline Euchlanis dilatata Ehrenberg, 1832 & + & - & + & + & - & - & - & - & + & - \\
\hline \multicolumn{11}{|l|}{ Cем. Brachionidae } \\
\hline Anuraeopsis fissa Gosse, 1851 & - & - & - & + & - & - & - & - & - & - \\
\hline Brachionus angularis bidens Plate, 1886 & - & + & + & + & + & - & + & + & + & + \\
\hline B. diversicornis diversicornis (Daday, 1883) & + & + & + & + & + & + & + & - & + & + \\
\hline B.d. homoceros (Wierzejski, 1891) & + & + & + & + & + & + & + & + & + & + \\
\hline B. leydigii Cohn, 1862 & - & - & - & - & - & - & - & + & + & - \\
\hline B. quadridentatus Hermann, 1783 & - & - & - & - & - & - & + & + & + & + \\
\hline B. q. melheni Barrois et Daday, 1894 & - & - & - & - & + & - & - & - & - & - \\
\hline B. q. brevispinus Ehrenberg, 1832 & + & - & - & - & - & - & - & - & - & - \\
\hline B. q. ancylognathus Schmarda, 1859 & - & - & + & + & + & - & - & - & - & - \\
\hline B. q. cluniorbicularis Skorikov, 1894 & + & - & + & + & + & + & - & - & - & - \\
\hline B. urceus (Linnaeus, 1758) & - & + & - & - & - & - & - & - & - & - \\
\hline Platyias quadricornis (Ehrenberg, 1832) & - & - & - & + & + & - & - & + & - & - \\
\hline Kellicottia longispina (Kellicott, 1879) & - & + & - & - & + & + & - & + & + & - \\
\hline Keratella cochlearis (Gosse, 1851) & - & - & - & - & - & - & + & + & + & - \\
\hline K. c. tecta $($ Gosse, 1851$)$ & - & + & + & + & + & - & + & + & + & + \\
\hline K. quadrata (O. F. Müller, 1786) & + & + & - & - & + & + & + & + & - & - \\
\hline \multicolumn{11}{|l|}{ Cем. Conochilidae } \\
\hline Conochilus unicornis Rousselet, 1892 & - & - & - & + & - & - & + & + & - & - \\
\hline \multicolumn{11}{|l|}{ Cем. Testudinellidae } \\
\hline Pompholyx sulcata Hudson, 1885 & - & - & + & - & - & - & + & + & - & - \\
\hline Testudinella caeca (Parsons, 1892) & - & - & + & - & - & - & - & - & - & - \\
\hline T. patina (Hermann, 1783) & - & - & + & - & - & + & - & + & - & - \\
\hline \multicolumn{11}{|l|}{$\begin{array}{c}\text { Сем. Filiniidae } \\
\end{array}$} \\
\hline Filinia longiseta (Ehrenberg, 1834) & - & - & + & + & - & - & - & + & - & - \\
\hline \multicolumn{11}{|l|}{ Cем. Collothecidae } \\
\hline Collotheca mutabilis (Hudson, 1885) & - & + & - & - & + & + & + & + & + & - \\
\hline \multicolumn{11}{|c|}{ COPEPODA } \\
\hline Cем. Cyclopidae & & & & & & & & & & \\
\hline Macrocyclops albidus (Jurine, 1820) & - & - & - & - & + & + & + & + & - & - \\
\hline M. fuscus (Jurine, 1820) & - & - & - & - & - & - & - & + & - & - \\
\hline
\end{tabular}


Окончание табл. 1

\begin{tabular}{|c|c|c|c|c|c|c|c|c|c|c|}
\hline 1 & 2 & 3 & 4 & 5 & 6 & 7 & 8 & 9 & 10 & 11 \\
\hline Eucyclops macruroides (Lilleborg, 1901) & + & - & - & + & + & - & + & + & - & - \\
\hline Paracyclops fimbriatus (Fischer, 1853) & + & - & - & - & - & - & - & - & - & - \\
\hline Mesocyclops leuckarti (Claus, 1857) & + & + & + & + & + & + & + & + & + & + \\
\hline Thermocyclops oithonoides (Sars, 1863) & - & + & + & + & + & + & + & + & + & + \\
\hline \multicolumn{11}{|l|}{ Cем. Diaptomidae } \\
\hline Eudiaptomus gracilis (Sars, 1863) & - & - & - & - & - & - & + & - & - & + \\
\hline \multicolumn{11}{|l|}{ Сем. Ameiridae } \\
\hline Harpacticoida sp. & - & - & - & - & + & - & - & - & - & - \\
\hline \multicolumn{11}{|c|}{ CLADOCERA } \\
\hline Cем. Sididae & & & & & & & & & & \\
\hline Sida crystallina (O. F. Müller, 1776) & + & - & - & + & + & + & - & + & - & - \\
\hline Diaphanosoma brachyurum (Liévin, 1848) & + & + & + & + & + & + & - & + & + & + \\
\hline \multicolumn{11}{|l|}{ Cем. Daphniidae } \\
\hline Daphnia cucullata Sars, 1862 & + & + & - & + & + & + & + & + & + & + \\
\hline D. cristata Sars, 1862 & + & - & - & - & - & - & - & - & - & - \\
\hline Simocephalus vetulus (O.F. Müller, 1776) & - & - & - & - & + & + & + & - & - & - \\
\hline Ceriodaphnia pulchella Sars, 1862 & + & - & - & + & + & + & + & + & - & - \\
\hline \multicolumn{11}{|l|}{ Ceм. Chydoridae } \\
\hline Eurycercus lamellatus (O. F. Müller, 1785) & - & - & - & - & - & + & - & - & - & - \\
\hline Pleuroxus aduncus (Jurine, 1820) & - & - & - & - & + & - & - & - & - & - \\
\hline Chydorus sphaericus (O.F. Müller,1785) & + & - & + & + & + & + & + & + & + & - \\
\hline Alona quadrangularis (O.F. Müller,1785) & - & - & + & - & + & - & - & + & - & - \\
\hline A. rectangula Sars, 1862 & - & - & + & + & + & - & - & + & - & - \\
\hline A. costata Sars, 1862 & - & - & - & + & - & - & - & - & - & - \\
\hline Acroperus harpae (Baird, 1837) & - & - & - & + & + & - & - & - & - & - \\
\hline Graptoleberis testudinaria (Fischer, 1848) & - & - & - & - & - & - & - & - & + & - \\
\hline \multicolumn{11}{|l|}{ Cем. Bosminidae } \\
\hline Bosmina longirostris (O. F. Müller, 1785) & + & + & + & + & + & + & + & + & + & - \\
\hline B. coregoni (Baird, 1857) & + & - & - & - & - & - & - & - & - & - \\
\hline \multicolumn{11}{|l|}{$\begin{array}{c}\text { Cем. Polyphemidae } \\
\end{array}$} \\
\hline Polyphemus pediculus (Linnaeus, 1778) & - & - & - & - & + & - & - & - & - & - \\
\hline \multicolumn{11}{|l|}{ Cем. Cercopagidae } \\
\hline Bythotrephes cederströmii Schoedler, 1877 & - & - & + & - & - & - & - & - & - & + \\
\hline \multicolumn{11}{|l|}{ Ceм. Leptodoridae } \\
\hline Leptodora kindtii (Focke, 1844) & + & - & - & - & - & - & - & - & + & + \\
\hline Число видов Rotifera & 10 & 16 & 16 & 14 & 15 & 12 & 16 & 18 & 12 & 9 \\
\hline Число видов Copepoda & 3 & 2 & 2 & 3 & 5 & 3 & 5 & 5 & 2 & 3 \\
\hline Число видов Cladocera & 9 & 3 & 6 & 9 & 12 & 8 & 5 & 8 & 6 & 4 \\
\hline Суммарное число видов & 22 & 21 & 24 & 26 & 32 & 23 & 26 & 31 & 20 & 16 \\
\hline
\end{tabular}

Таблииа 2

Процентное соотношение основных групп зоопланктона

\begin{tabular}{|c|c|c|c|c|c|c|}
\hline \multirow{2}{*}{ Станция } & \multicolumn{3}{|c|}{ По численности } & \multicolumn{3}{c|}{ По биомассе } \\
\cline { 2 - 7 } & Rotifera & Сорероda & Cladocera & Rotifera & Copepoda & Cladocera \\
\hline 1 & 9 & 86 & 5 & 5 & 91 & 4 \\
\hline 2 & 46 & 52 & 2 & 38 & 61 & 1 \\
\hline 3 & 25 & 72 & 3 & 23 & 74 & 3 \\
\hline 4 & 32 & 65 & 3 & 29 & 63 & 8 \\
\hline 5 & 21 & 76 & 3 & 12 & 82 & 6 \\
\hline 6 & 5 & 94 & 1 & 5 & 92 & 3 \\
\hline 7 & 65 & 34 & 1 & 61 & 38 & 1 \\
\hline 8 & 51 & 47 & 2 & 28 & 66 & 6 \\
\hline 9 & 14 & 85 & 1 & 16 & 82 & 2 \\
\hline 10 & 18 & 80 & 2 & 5 & 92 & 3 \\
\hline
\end{tabular}


Относительно открытой части озера зоопланктон заросшей литорали отличался высокими показателями численности, биомассы, индекса удельного видового богатства, отношения $B_{\text {Crust }} / B_{\text {Rot }}$ (табл. 3).

Таблица 3

Характеристика зоопланктона различных участков оз. Яхробольское

\begin{tabular}{|c|c|c|c|c|c|c|c|c|}
\hline \multirow{2}{*}{ Показатель } & \multicolumn{4}{|c|}{ Заросшая макрофитами литораль } & \multicolumn{4}{|c|}{ Центральная открытая часть } \\
\hline & Rotifera & Copepoda & Cladocera & Общая & Rotifera & Copepoda & Cladocera & Общая \\
\hline$N$, тыс. ЭКз. $/ \mathrm{M}^{3}$ & 333 & 1207 & 34 & 1574 & 240 & 273 & 12 & 525 \\
\hline$B, \Gamma / \mathrm{M}^{3}$ & 1,06 & 5,59 & 0,22 & 6,87 & 0,75 & 1,19 & 0,03 & 1,97 \\
\hline$H_{N}$, бит/Экз. & - & - & - & 2,26 & - & - & - & 3,09 \\
\hline$H_{B}$, бит/экз. & - & - & - & 2,33 & - & - & - & 2,70 \\
\hline$D_{M g}$ & - & - & - & 1,68 & - & - & - & 1,52 \\
\hline$d$ & - & - & - & 0,51 & - & - & - & 0,37 \\
\hline$B_{\text {Crust }} / B_{\text {Rot }}$ & - & - & - & 7,13 & - & - & - & 1,62 \\
\hline$W_{c p,}, \mathrm{M \Gamma}$ & - & - & - & 0,0043 & - & - & - & 0,0037 \\
\hline
\end{tabular}

Величины индексов Шеннона и доминирования свидетельствовали о заметном снижении выравненности видов в заросшем макрофитами мелководье. Средняя индивидуальная масса зоопланктера для озера в целом составляла 0,004 мг, что характерно для водоемов эвтрофного типа [1]. Все участки водоема по величине индекса трофности $\left(E_{c p .}=4,0\right)$ также характеризовались как эвтрофные.

\section{Выводы}

Количественные показатели зоопланктона говорят о значительных трофических ресурсах оз. Яхробольское, особенно в заросшей макрофитами литорали. По рассмотренным структурным показателям озеро можно отнести к эвтрофному типу. Как указывает И. Н. Андроникова [1], большое распространение в планктоне коловраток, характеризующихся короткими и более простыми жизненными циклами, а также доминирование и высокие количественные величины младших возрастных стадий ракообразных в период активного функционирования сообщества характеризуют водоем как эвтрофный. Преобладание в составе зоопланктона $\beta$ и $\alpha-\beta$-мезосапробов, особенно многочисленных брахионусов, свидетельствует о загрязнении водоема.

\section{Библиографические ссылки}

1. Андроникова И. Н. Структурно-функциональная организация зоопланктона озерных экосистем. - СПб. : Наука, 1996. - 189 с.

2. Методика изучения биогеоценозов внутренних водоемов. - М. : Наука, 1975. -240 c.

3. Мэгарран Э. Экологическое разнообразие и его измерение. - М. : Мир, 1992. - 182 c.

4. Фортунатов М. А. Озера Ярославской области: Кадастровое описание и краткие лимнологические характеристики. VII. Озера, расположенные в левой пойме Волги в пределах Костромской низины / М. А. Фортунатов, Б. Д. Московский // Озера Ярославской области и перспективы их хозяйственного использования. - Ярославль : Яросл. гос. пед. ин-т, Яросл. отд. Геогр. о-ва СССР, 1970. - С. 106-160.

5. Цихон-Луканина Е. А. О зоопланктоне и зообентосе некоторых озер Ярославской области / Е. А. Цихон-Луканина, 3. Н. Чиркова // Озера Ярославской области и перспективы их хозяйственного использования. - Ярославль : Яросл. гос. пед. ин-т, Яросл. отд. Геогр. о-ва СССР, 1970. - C. 319-325.

Надійшла до редколегії 18.09.2010 